\title{
EFEKTIVITAS PROGRAM BACK SCHOOL DAN TEKNIK MCKENZIE PADA PASIEN NYERI PUNGGUNG BAWAH
}

\author{
Saifudin Zuhri, Marti Rustanti \\ Kementerian Kesehatan Politeknik Kesehatan Surakarta Jurusan Fisioterapi
}

\begin{abstract}
Back School Program, Mckenzie Techniques, Pain, Vas, Patients With Low Back Pain. On the other hand needed McKenzie method for relaxation to the muscles of the back due to spasm, so that the pain can be reduced. To prove the effectiveness of the program back school and McKenzie techniques in reducing lower back pain. Types of Research: experimental study. Two group pre test-post test design. Place and Time Research in Unit physiotherapy Hospital Dr Moewardi Surakarta from January to June 2015. Sample: lower back pain patients who met the study criteria. Research variables: independent variable is a back school program and McKenzie techniques, while the dependent variable was pain. The research data in the form of pain measured by VAS. Data obtained include scale ratio. Statistical Analysis: The subjects in one group <30 people, then analyzed with nonparametric tests. Homogeneity of data were tested with the Mann-Whitney test was obtained $p=$ 0.030 ( $P<0.05)$ indicates the data are not homogeneous. Wilcoxon test group I obtained $p=0.000$ ( $p<0.05$ ) showed no difference effect of back school programs to decrease lower back pain. Wilcoxon test group II obtained $p=0.000(p<0.05)$ showed no difference effect of McKenzie technique to decrease lower back pain. Mann-Whitney test after treatment was obtained $p=0.006(p<0.05)$ showed no difference in effectiveness between the back school program with McKenzie techniques in reducing lower back pain. Results of the mean difference in pain reduction anatara back school program with the technique gained 9.71 higher McKenzie Techniques. McKenzie Technique is more effective than a back school program to reduce lower back pain.
\end{abstract}

Keywords: Back School Program, Mckenzie Techniques, Pain, Vas, Patients With Low Back Pain

\begin{abstract}
Abstrak: Program Back School, Teknik Mckenzie, Pain, Vas, Pasien Dengan Low Back Pain. Di sisi lain diperlukan metode McKenzie untuk relaksasi untuk otototot kembali karena kejang, sehingga rasa sakit bisa dikurangi. Untuk membuktikan efektivitas program kembali sekolah dan teknik McKenzie dalam mengurangi nyeri punggung bawah. Jenis Penelitian: Penelitian eksperimental. Dua kelompok desain pre test-post test. Tempat dan Waktu Penelitian di Unit fisioterapi Rumah Sakit Dr Moewardi Surakarta dari Januari sampai Juni 2015. Sampel: kembali pasien sakit yang memenuhi kriteria penelitian yang lebih rendah. variabel penelitian : variabel bebas adalah program sekolah kembali dan teknik McKenzie, sedangkan variabel dependen adalah rasa sakit. Data penelitian berupa nyeri diukur dengan VAS. Data yang diperoleh meliputi rasio skala. Analisis statistik: Subyek dalam satu kelompok
\end{abstract}


$<30$ orang, kemudian dianalisis dengan uji nonparametrik. Homogenitas data diuji dengan uji Mann-Whitney diperoleh $\mathrm{p}=0.030(\mathrm{P}<0,05)$ menunjukkan data yang tidak homogen. kelompok uji Wilcoxon saya diperoleh $\mathrm{p}=0,000(\mathrm{p}<0,05)$ tidak menunjukkan efek perbedaan program sekolah kembali untuk mengurangi nyeri punggung bawah. Wilcoxon tes kelompok II diperoleh $\mathrm{p}=0,000(\mathrm{p}<0,05)$ tidak menunjukkan efek perbedaan teknik McKenzie untuk mengurangi nyeri punggung bawah. uji Mann-Whitney setelah pengobatan diperoleh $\mathrm{p}=0,006(\mathrm{p}<0,05)$ menunjukkan tidak ada perbedaan dalam efektivitas antara program sekolah kembali dengan teknik McKenzie dalam mengurangi nyeri punggung bawah. Hasil dari perbedaan berarti sakit pengurangan anatara kembali program sekolah dengan teknik yang diperoleh 9,71 lebih tinggi Teknik McKenzie. McKenzie Teknik ini lebih efektif daripada program sekolah kembali untuk mengurangi nyeri punggung bawah.

Kata Kunci : Program Back School, Teknik Mckenzie, Pain, Vas, Pasien Dengan Low Back Pain

\section{PENDAHULUAN}

Nyeri punggung bawah merupakan suatu permasalahan yang sering ditemukan dan mengenai kirakira 60-80\% populasi selama hidupnya. Kasus yang didapatkan terkait kelainan anatomis 20-30\% dari semua kasus yang sering dijumpai, dan sebanyak 70-80\% idiopatik. Sebagian besar NPB sembuh spontan setelah 4-6 minggu apapun jenis terapi yang diberikan namun dapat berulang pada 2/3 dari kasus beberapa tahun kemudian. Sekitar $10 \%-25 \%$ nyeri punggung bawah tidak membaik dalam 4-6 minggu dan menetap menjadi kronis. Review sistematis memperkirakan prevalensi NPB berkisar $12-33 \%$, prevalensi satu tahun rentang NPB 22-65\%, dan seumur hidup rentang NPB 11- 84\%.

Gejala awal nyeri punggung bawah mulai usia produktif 25-30 tahun sampai usia 50 tahun sehingga mengakibatkan kerugian produktivitas. NPB merupakan masalah ekonomi yang penting di seluruh dunia.
Berbagai kemungkinan terapi yang tersedia untuk pasien NPB kronis meliputi program pendidikan, perilaku kognitif, obat-obatan, elektronik dan terapi termal, terapi manual, dan olahraga $^{14}$. Sebagian besar terapi ini direkomendasikan oleh pengelolaan NPB kronis Eropa, di mana pilihan latihan dengan program pendidikan dan diikuti prinsip-prinsip terapi perilaku kognitif dianggap lebih efektif.

Program back school berupa pendekatan pengobatan berbasis kelompok dan latihan McKenzie berupa pendekatan pengobatan berbasis individu merupakan metode terapi pilihan yang menjanjikan untuk pengobatan NPB di antaranya untuk memberikan informasi teoritis dalam rangka mendidik pasien tentang kondisi, sehingga pasien lebih mampu memahami kondisi dan bagaimana untuk mengubah perilaku terhadap kejadian NPB.

$$
\text { McKenzie tahun }
$$

mengusulkan terapi individu untuk NPB yang disebut metode McKenzie. Metode McKenzie terdiri atas tiga langkah yaitu 
evaluasi, pengobatan, dan pencegahan. Langkah evaluasi menggunakan gerakan berulang-ulang dan pengaturan posisi di punggung bawah dan tungkai bawah. Latihan yang tepat dalam metode McKenzie didasarkan pada arah sebagai pengurangan rasa sakit, sentralisasi gejala, dan pemulihan nyeri total. Langkah pencegahan terdiri dari mendidik dan mendorong pasien untuk berolahraga secara teratur dan self-care.

\section{METODE PENELITIAN}

Penelitian ini adalah merupakan penelitian eksperimen semu dengan desain two groups pre and post test design Penelitian ini dilaksanakan di poli fisioterapi RSUD Dr. Moewardi Surakarta dan dilaksanakan mulai bulan Januari sampai dengan Juni 2015

Subyek penelitian adalah pasien NPB yang berobat ke Poli Fisioterapi RSUD Dr Moewardi Surakarta yang memenuhi kriteria inklusi dan eksklusi. Kriteria inklusi meliputi: (1) pasien nyeri punggung bawah, (2) NPB > 3 bulan, (3) berusia antara 18 - 70 tahun, (4) bersedia menjadi subyek penelitian. Sedangkan kriteria eksklusinya adalah: (1) adanya kontraindikasi untuk latihan fisik, (2) pasien dengan patologi serius tulang belakang, penyakit kardiorespirasi dan kehamilan. Untuk kriteria drop out meliputi: (1) tidak mengikuti latihan lebih dari 3 kali, (2) tidak hadir waktu evaluasi hasil penelitian. Variabel dalam penelitian ini adalah: (1) variabel bebas berupa program back school dan latihan McKenzie, (2) variabel terikat berupa nyeri.

Peralatan yang digunakan untuk mengukur nyeri pasien terdiri atas: blangko VAS dan blanko pencatatan pelaksanaan penelitian. Kelompok satu mendapatkan program back school dan terapi rutin RSUD Dr Moewardi. Kelompok dua mendapatkan latihan McKenzie dan terapi rutin RSUD Dr Moewardi Surakarta. Data VAS yang dikumpulkan baik pre test maupun post test, dianalisis menggunakan bantuan software SPSS. Berhubung jumlah subyek pada masing-masing kelompok penelitian < 30 orang, maka distribusi data sulit mencapai normal. Sehingga data nyeri berupa skala rasio diuji secara nonparametric dengan uji beda dalam kelompok dengan Wilcoxon test dan uji antar kelompok dengan Mann-Whitney test.

\section{HASIL PENELITIAN}

Karakteristik subyek berdasarkan jenis kelamin, distribusi laki-laki dalam kelompok I sebanyak 7 orang (33\%) dan wanita sebanyak 14 orang (67\%). Sedangkan pada kelompok II, distribusi laki-laki adalah sebanyak 6 orang (30\%) dan wanita adalah sebanyak 14 orang (70\%).

\section{Tabel 1}

Karakteristik Subyek Berdasarkan Jenis Kelamin

\begin{tabular}{ccccc}
\hline NO & Kelompok & \multicolumn{2}{c}{ Jenis kelamin } & Jumlah \\
\cline { 3 - 5 } & & $\begin{array}{c}\text { Laki- } \\
\text { laki }\end{array}$ & Wanita & \\
\cline { 3 - 5 } 1 & I & 7 & 14 & 21 \\
& & $(33 \%)$ & $(67 \%)$ & orang \\
2 & II & 6 & 14 & 20 \\
& & $(30 \%)$ & $(70 \%)$ & orang \\
\hline & n & 13 & 28 & 41 \\
& & orang & orang & orang \\
\hline
\end{tabular}

Adapun karakteristik subyek berdasarkan usia, untuk kelompok I ratarata usia adalah 60.14 tahun, dengan usia 
termuda 51 tahun dan usia tertua 70 tahun. Sedangkan pada kelompok II distribusi usia rata-rata usia adalah 60 tahun, dengan usia termuda 51 tahun dan usia tertua 69 tahun.

Tabel 2

\section{Karakteristik Subyek Berdasarkan}

\section{Usia}

\begin{tabular}{cccccc}
\hline Kel & $\mathrm{n}$ & Minim & Maksim & Mean & SD \\
\hline I & 21 & 51 & 70 & 60.19 & 5.627 \\
II & 20 & 51 & 69 & 60 & 4.577 \\
\hline
\end{tabular}

Sedangkan karakteristik subyek berdasarkan pendidikan yaitu untuk kelompok I: lulus pendidikan dasar sebanyak 5 orang (24\%), lulus pendidikan menengah sebanyak 13 orang $(62 \%)$, lulus pendidikan perguruan tinggi sebanyak 3 orang (14\%). Sedangkan untuk kelompok penelitian II yaitu: lulus pendidikan dasar sebanyak 3 orang (15\%), lulus pendidikan menengah sebanyak 15 orang $(75 \%)$, (3) lulus pendidikan perguruan tinggi sebanyak 2 orang (10\%).

Tabel 3

\section{Karakteristik Subyek Berdasarkan}

Pendidikan

\begin{tabular}{|c|c|c|c|c|c|}
\hline \multirow[b]{2}{*}{ NO } & \multirow[b]{2}{*}{ Kelompok } & \multicolumn{3}{|c|}{ Pendidikan } & \multirow[b]{2}{*}{$\mathrm{n}$} \\
\hline & & $\mathrm{SD}$ & $\begin{array}{l}\text { SMP } \\
\text { SMA }\end{array}$ & PT & \\
\hline 1 & $\mathrm{I}$ & $\begin{array}{c}5 \\
(24 \%)\end{array}$ & $\begin{array}{c}13 \\
(62 \%)\end{array}$ & $\begin{array}{c}3 \\
(14 \%)\end{array}$ & $\begin{array}{c}21 \\
\text { orang }\end{array}$ \\
\hline 2 & II & $\begin{array}{c}3 \\
(15 \%)\end{array}$ & $\begin{array}{c}15 \\
(75 \%)\end{array}$ & $\begin{array}{c}2 \\
(10 \%)\end{array}$ & $\begin{array}{c}20 \\
\text { orang }\end{array}$ \\
\hline & $\mathrm{N}$ & $\begin{array}{c}13 \\
\text { orang } \\
\end{array}$ & $\begin{array}{c}28 \\
\text { orang } \\
\end{array}$ & $\begin{array}{c}5 \\
\text { orang } \\
\end{array}$ & $\begin{array}{c}41 \\
\text { orang }\end{array}$ \\
\hline
\end{tabular}

Pada kelompok I, nilai VAS ratarata pre-test adalah $48.57 \mathrm{~mm}$ dan posttest adalah $34.29 \mathrm{~mm}$, sehingga selisih pre-test dan post test nilai VAS adalah $14.29 \mathrm{~mm}$.
Tabel 4

Keadaan Awal-Akhir Subyek Penelitian Kelompok I

\begin{tabular}{cccccc}
\hline Kel I & n & Min & Maks & Rerata & SD \\
\hline VAS & 21 & 20 & 80 & 48.57 & 14.243 \\
T0 & & & & & \\
VAS & 21 & 10 & 60 & 34.29 & 16.605 \\
T8 & & & & & \\
\hline
\end{tabular}

Sedangkan pada kelompok II, nilai VAS rata-rata pre-test adalah 62 $\mathrm{mm}$ dan post-test adalah $38 \mathrm{~mm}$, sehingga selisih pre-test dan post test nilai VAS adalah $24 \mathrm{~mm}$.

Tabel 5

Keadaan Awal-Akhir Subyek Penelitian Kelompok II

\begin{tabular}{cccccc}
\hline Kel II & $\mathrm{n}$ & Min & Maks & Rerata & SD \\
\hline VAS & 20 & 30 & 90 & 62.00 & 18.525 \\
T0 & & & & & \\
VAS & 20 & 0 & 80 & 38.00 & 20.417 \\
T8 & & & & & \\
\hline
\end{tabular}

Uji homogenitas data antara data kelompok I dan kelompok II dianalisis dengan Mann Whitney test didapatkan $p$ $=0.030(p<0,05)$, artinya data tidak homogen

\section{Tabel 6}

Hasil Analisis Uji Homogenitias Data

\begin{tabular}{|c|c|c|c|c|}
\hline AS & $\begin{array}{c}\text { Mann- } \\
\text { Whitney U }\end{array}$ & $\begin{array}{l}\text { Wilcoxon } \\
\text { W }\end{array}$ & $\mathrm{Z}$ & $\begin{array}{l}\text { Asymp. } \\
\text { Sig. (2- } \\
\text { tailed) }\end{array}$ \\
\hline T0 & .500 & 359 & -2.172 & 0.030 \\
\hline \multicolumn{5}{|c|}{$\begin{array}{l}\text { Pada uji hipotesi } 1 \text {, uji pre test- } \\
\text { test dengan uji Wilcoxon } \\
\text { kan } p=0.000(p<0.05) \text {. Hasil } \\
\text { uji ini menunjukkan ada } \\
\text { engaruh program back school } \\
\text { p penurunan nyeri penderita }\end{array}$} \\
\hline
\end{tabular}
NPB. 
Tabel 7

Hasil Uji Statistik Wilcoxon Test Pada Hipotesis I

\begin{tabular}{cccc}
\hline & $\mathrm{N}$ & $\mathrm{Z}$ & $\begin{array}{c}\text { Asymp, Sig (2- } \\
\text { tailed) }\end{array}$ \\
\hline $\begin{array}{c}\text { VAS T0- } \\
\text { T8 }\end{array}$ & 21 & -3.563 & 0.000 \\
\hline
\end{tabular}

Pada uji hipotesi II, uji pre testpost test dengan uji Wilcoxon didapatkan $p=0.000(p<0.05)$. Hasil dari uji ini menunjukkan ada beda/pengaruh program latihan McKenzie terhadap penurunan nyeri penderita NPB.

\section{Tabel 8}

Hasil Uji Statistik Wilcoxon Test Pada Hipotesis II

\begin{tabular}{cccc}
\hline & $\mathrm{N}$ & $\mathrm{Z}$ & $\begin{array}{c}\text { Asymp, Sig (2- } \\
\text { tailed) }\end{array}$ \\
\hline $\begin{array}{c}\text { VAS T0- } \\
\text { T8 }\end{array}$ & 20 & - & 0.000 \\
\hline
\end{tabular}

Pada uji hipotesi III, uji beda dengan Mann Whitney test, didapatkan $\mathrm{p}$ $=0.06(\mathrm{p}<0,05)$. Hasil uji ini menunjukkan ada beda pengaruh antara program back school dengan pemberian McKenzie.

\section{Tabel 9}

Hasil Uji Statistik Mann-Whitney Test Pada Hipotesis III

\begin{tabular}{ccccc}
\hline VAS & n Kel & n Kel & Z & $\begin{array}{c}\text { Asymp, } \\
\text { T0-T8 }\end{array}$ \\
& II & & $\begin{array}{c}\text { Sig (2- } \\
\text { tailed) }\end{array}$ \\
\hline & 21 & 20 & -2.767 & 0.006 \\
\hline
\end{tabular}

Melihat hasil analisis uji beda pengaruh menunjukkan ada beda pengaruh yang lebih efektif, terhadap penurunan nyeri penderita NPB. Hal ini ditunjukkan nilai selisih rata-rata yaitu kelompok program back school sebesar 14,29. Sedangkan nilai selisih rata-rata pada kelompok Mc Kenzie bernilai 24 . Sehingga hasil analisis ini menunjukkan perlakuan Mc Kenzie lebih baik dari program backschool terhadap penurunan nyeri penderita NPB.

\section{PEMBAHASAN}

Subyek dalam kelompok back school akan memahami mekanisme yang menyebabkan nyeri, sehingga akan berhati-hati terhadap aktifitas yang memprovokasi nyeri baik pada saat bekerja maupun saat rekreasi, maupun istirahat. Selain memahami bantuan demonstrasi dan mendiskusikan penampilan yang tepat dari latihan. Subyek akan mengkondisikan perilaku ergonomi dalam aktifitas sehari-hari, sehingga provokasi terahadap aktifitas kontraksi otot tidak seimbang akan memicu nyeri bisa dikendalikan. Penambahan back school dapat mengurangi spasme otot, memperbaiki sirkulasi, kelenturan jaringan lunak dan mobilisasi sendi, menguatkan otot-otot yang lemah, memperbaiki kontrol gerakan punggung, memperbaiki kebiasaan sikap yang salah sehingga nyeri akan berkurang/menurun bahkan hilang.

Hasil penelitian ini sejalan dengan penelitian berjudul "Effectiveness of back school for treatment of pain and functional disability in patients with chronic low back pain: a randomized controlled trial"19 didapatkan adanya efektivitas penambahan back school untuk terapi nyeri dan fungsional. Hal ini juga sejalan dengan penelitian berjudul "Quality of 
life by multidisciplinary back school program in patients with chronic nonspesific low back pain: a single blind randomized controlled trial" 16 diperoleh program back school efektif untuk kasus LBP non-spesifik.

Prinsip terapi latihan Mc kenzie adalah memperbaiki postur untuk mengurangi hiperlordosis lumbal, penurunan spasme otot melalui efek relaksasi, membebaskan kekakuan sendi intervertebralis dan koreksi postur yang buruk. Jaringan tubuh terutama pada otot-ototnya terbentuk dari serat-serat halus (myofibril), dalam keadaan spasme sering mengalami perlengketan satu sama lain (crosslink). Hal ini jika langsung dilakukan gerakan, kemungkinkan besar akan merusak crosslink tersebut. Karena itu untuk melepaskan perlengketan tadi setelah dilakukan terapi standar seperti pemanasan dan dilakukan peregangan latihan McKenzie. Selanjutnya, otot-otot sudah dapat melakukan gerakan yang memerlukan penguluran, sendi-sendi sudah menjadi longgar, siap melakukan gerakan yang lebih keras dan memerlukan ruang gerak yang maksimal. Penurunan nyeri terjadi kemungkinan disebabkan oleh mekanisme latihan yang menggunakan prinsip perbaikan vaskularisasi sehingga terjadi removal metabolit dan algogenic pain. Di samping latihan Mc kenzie akan mengurangi tekanan pada bagian posterior annulus fibrosus melalui gerakan-gerakan ekstensi, sehingga nyeri berkurang.

Hasil penelitian ini sejalan dengan Clare et $\mathrm{al}^{4}$ dalam "A systematic review of efficacy of McKenzie therapy for spinal pain", meskipun didapatkan adanya efektivitas terapi McKenzie sama dengan terapi standar lainnya untuk perbaikan nyeri spinal. Hasil penelitian berjudul "Treatment of nonspecific low back pain: McKenzie versus traditional treatment"6 didapatkan efektivitas McKenzie pada tahap awal terapi terjadi penurunan nyeri lebih besar pada NPB non spesifik.

Hasil analisis Mann-Whitney test menunjukkan intervensi program back school dengan latihan Mc Kenzie setelah pemberian terapi standar ternyata memberikan hasil perbedaan yang signifikan $(\mathrm{p}<0,05)$. Melihat selisih mean di mana latihan Mc Kenzie lebih baik dari pemberian program back school terkait dengan karakteristik subyek berdasarkan pendidikan, kelompok back school untuk lulusan SD lebih banyak dan lulusan sekolah menengah lebih sedikit sedangkan untuk perguruan tinggi lebih banyak kelompok Mc Kenzie. Hal ini akan berpengaruh terhadap efektifitas program edukasi back school kurang optimal.

Di sisi lain potensi kelompok Mc Kenzie lebih baik adalah konsistensi subyek untuk melakukan program lebih serius dan teratur jika termonitor secara langsung seperti dalam pelaksanaan terapi latihan Mc Kenzie yang terawasi. Hal ini berbeda dengan program back school yang meletakkan kesadaran subyek untuk melakukan aktifitas seharihari secara sadar dan tidak mendapati perlakuan terapi latihan. Hal ini kurang sejalan dengan penelitian berjudul "Effectiveness of Back School Versus McKenzie Exercises in Patients With Chronic Nonspecific Low Back Pain: A Randomized Controlled Trial", didapatkan minimal lebih baik latihan 
McKenzie untuk fungsionalnya dan untuk penurunan nyeri sama-sama efektif dan tidak ada perbedaan yang bermakna, di mana tingkat pendidikan dan motivasi jelas berbeda dengan subyek penelitian yang belum terkondisi seperti dalam penelitian ini.

\section{KESIMPULAN DAN SARAN}

Kesimpulan dari penelitian ini adalah: (1) program back school dapat menurunkan nyeri penderita NPB, (2) latihan McKenzie dapat menurunkan nyeri penderita NPB, (3) latihan McKenzie lebih efektif daripada program back school untuk penurunan nyeri penderita NPB.

Berdasarkan pelaksanaan dan hasil penelitian yang telah dilakukan, disarankan: jumlah sampel untuk penelitian yang akan datang lebih banyak, misalnya di rumah sakit atau tempat praktek fisioterapi. Karakteristik subyek penelitian terutama tingkat pendidikan dikendalikan penyebarannya yang merata terkait penelitian program back school yang melibatkan unsur pendidikan. Dilakukan pengembangan penelitian dengan memperhatikan faktorfaktor yang mempengaruhi penurunan nyeri penderita NPB.

\section{DAFTAR RUJUKAN}

Clare, Helen A, , Roger Adams, Christopher G Maher, 2004, A systematic review of efficacy of McKenzie therapy for spinal pain, Australian Journal of Physiotherapy Volume 50, Issue 4, Pages 209-216

Mc Kenzie, R, 1997. Treat Your Own Back. New Zealand : Spinal Publication Ltd

Vitriana, 2011, Back School Sebagai Salah Satu Manajemen Terapi Konservatif Untuk Nyeri Punggung Bawah, http://repository.unpad.ac.id/han dle/123456789/1536

Yanuar, Andre. 2002. Anatomi, Fisiologi dan Biomekanika Tulang Belakang. Simposium Pelantikan Dokter Periode 142. Solo. 